\title{
POLUIÇÃO E A DENSIDADE DE VEGETAÇÃO: BTEX EM ALGUMAS ÁREAS PÚBLICAS DE CURITIBA - PR, BRASIL
}

\author{
Ana Flavia Locateli Godoi* e Ricardo Henrique Moreton Godoi \\ Curitiba - PR, Brasil \\ Roosevelt de Azevedo e Leila Teresinha Maranho \\ Universidade Positivo, Rua Prof. Pedro V. Parigot de Souza, 5300, 81280-330 Curitiba -PR, Brasil
}

Departamento de Engenharia Ambiental, Universidade Federal do Paraná, Rua Francisco H. dos Santos, 100, 81531-990

Recebido em 4/5/09; aceito em 27/10/09; publicado na web em 9/3/10

\begin{abstract}
POLLUTION AND DENSITY OF VEGETATION: BTEX IN SOME PUBLIC AREAS OF CURITIBA - PR, BRAZIL. The occurrence of benzene, toluene, ethylbenzene, and xylenes (BTEX) in some public areas of Curitiba-PR, Brazil, was evaluated. Their concentrations were then related to the vegetation's density in each area. Average benzene concentrations varied from 3.9 to $6.1 \mu \mathrm{g}$ $\mathrm{m}^{-3}$, with higher values occurring in poorly dense vegetation areas. For toluene, average concentrations ranged from 6.5 to $7.2 \mu \mathrm{g}$ $\mathrm{m}^{-3}$. The effect of such pollutants was evaluated by means of a bio indicator, Tillandsia stricta. Variation in total chlorophyll content and in stomatic density were detected in some samples and may be related to the BTEX concentrations found in the studied areas.
\end{abstract}

Keywords: BTEX; urban traffic; bioindication.

\section{INTRODUÇÃO}

Com o progresso, o crescimento da população, a urbanização e o aumento da frota de veículos automotivos, observa-se um aumento progressivo na taxa de emissões de poluentes atmosféricos, tendo como consequência grandes problemas ambientais. Em ambientes externos, os principais responsáveis pelo aumento da poluição do ar são os processos de industrialização e urbanização, ocorridos com maior intensidade no século XX, destacando-se a queima de combustíveis fósseis por veículos automotores (combustão, perdas evaporativas na armazenagem e na distribuição de combustíveis), fontes fixas industriais e fumaça de cigarros. ${ }^{1,2}$

Entre os principais poluentes presentes em centros urbanos estão os compostos orgânicos voláteis (COVs), emitidos predominantemente pelos veículos automotores. Os COVs que têm proporcionado grande interesse científico para a qualidade do ar em áreas internas e externas são, especificamente, benzeno, tolueno, etillbenzeno e xilenos (BTEX), ${ }^{2-4}$ devido ao seu elevado grau de toxicidade ${ }^{2,5} \mathrm{e}$ ao fato de se concentrarem muito próximo ao solo, em função das suas densidades serem maiores que a densidade do ar atmosférico. A Organização Mundial da Saúde ${ }^{5}$ estimou que concentrações de benzeno de 1,7 $\mu \mathrm{g}$ $\mathrm{m}^{-3}$ podem causar 10 casos de leucemia em cada 1 milhão de habitantes.

Estudos realizados por diversos autores em diferentes cidades do Brasil, tendo como principal fonte as emissões veiculares em centros urbanos, registram concentrações crescentes de BTEX. ${ }^{6,7}$ Mas ainda são poucos os estudos que relacionam a poluição causada por tais compostos com a saúde humana ou a vegetação. ${ }^{8}$

O número de veículos que circulam na cidade de Curitiba só tem aumentado, consistindo atualmente de 1.073 .541 veículos licenciados, ${ }^{9}$ além de 1980 ônibus urbanos, transportando diariamente 2 milhões de pessoas..$^{10}$ Entretanto, a despeito desses dados, não existem estudos visando a avaliação das consequências da poluição atmosférica na cidade, o que motivou o desenvolvimento desta pesquisa.

Os efeitos prejudiciais das emissões veiculares sobre as plantas expostas ao lado de rodovias são relatados em diversos estudos. ${ }^{11-14} \mathrm{Ex}-$ perimentos realizados por Song et al. ${ }^{15}$ demonstraram que a redução das

*e-mail: aflgodoi@ufpr.br concentrações de BTEX em áreas internas é diretamente proporcional ao aumento da quantidade de plantas presentes.

Considera-se, em muitos estudos publicados, que os COVs são biologicamente ativos, uma vez que são compostos que participam dos processos físico-químicos do metabolismo da planta. ${ }^{16,17}$ Portanto, segundo Cape, ${ }^{18}$ as plantas podem metabolizar, transportar e acumular os COVs nas folhas, vacúolos ou parede celular ou conduzir estes compostos, através de suas raízes, para o solo.

As informações sobre a poluição atmosférica podem ser inferidas comparando-se a concentração da substância em estudo no tecido da planta. Tal análise apresenta menor custo para obtenção de informações sobre a qualidade ambiental de um local. ${ }^{19}$ Para avaliação do impacto causado na vegetação, o órgão mais estudado tem sido a folha, abordando-se principalmente alterações nas taxas fotossintéticas e respiratória ${ }^{20}$ e aspectos estruturais, como reflexo das alterações metabólicas. ${ }^{21}$ Entre os parâmetros mais estudados para avaliação da estrutura das folhas da planta estão os teores de clorofila total, a densidade estomática e a mensuração dos tecidos foliares.

\section{PARTE EXPERIMENTAL}

\section{Áreas de estudo}

As áreas de estudo foram definidas tomando como critério a densidade de vegetação, buscando-se diferentes cenários para fins de comparação. Três áreas distintas foram selecionadas e assim classificadas: com vegetação densa, pouco densa e esparsamente densa, em função do número e espaçamento dos indivíduos observados em campo. A escolha dos pontos de amostragem foi feita com base na direção predominante dos ventos e no volume de tráfego das ruas adjacentes ao local selecionado. Vale ressaltar que não há interferências de outras fontes fixas (como as provenientes de indústrias, por exemplo) em nenhuma das áreas avaliadas.

Dados de temperatura média diária, umidade relativa do ar e velocidade/direção do vento, utilizados na interpretação dos resultados obtidos, foram gentilmente cedidos pelo Instituto Tecnológico SIMEPAR, órgão responsável pela rede de monitoramento meteorológico do estado do Paraná. 
As amostragens foram realizadas durante 3 semanas consecutivas, divididas em 3 períodos de 7 dias, a saber: 28/07 a 04/08, 04/08 a 10/08 e 10/08 a 16/08/08. Foi realizada também uma contagem empírica dos veículos automotivos que circularam diariamente nas ruas próximas às áreas de estudos, considerando três cenários de abrangência (período de trânsito normal, intenso e noturno), resultando na quantidade média diária de veículos.

Devido ao fato dos BTEX apresentarem densidade maior que a do ar, e por isso se concentrarem próximos ao solo, ${ }^{2}$ os amostradores foram posicionados a uma altura média de $1,5 \mathrm{~m}$ (próximos à zona de respiração dos indivíduos), conforme critério adotado por Zabiegala et al.. ${ }^{22}$ Os amostradores foram protegidos da chuva e do vento por meio de aparatos de plástico.

\section{Passeio Público (PP)}

O Passeio Público (PP), classificado como área com vegetação pouco densa, foi o primeiro parque criado em Curitiba. Inaugurado em 1886, tem cerca de 70 mil m² de vegetação natural, na região central da cidade. Foi também o primeiro zoológico e, até hoje, possui alguns animais em cativeiro.

Os pontos de amostragens selecionados para o Passeio Público (PP) estão detalhados na Tabela 1, sendo indicados através das coordenadas Sul (S) e Oeste (O). O fluxo médio de veículos representa a média horária para os períodos de tráfego intenso (início da manhã e final de tarde).

Tabela 1. Pontos de amostragem de BTEX definidos para o PP

\begin{tabular}{|c|c|c|}
\hline Ponto & Localização & Coordenadas \\
\hline PP1 & $\begin{array}{c}\text { Ilha } \\
\text { (Próximo a uma via de grande tráfego, com fluxo } \\
\text { médio de } 1.600 \text { veículos por hora) }\end{array}$ & $\begin{array}{l}25^{\circ} 42^{\prime} 56^{\prime \prime} \mathrm{S} \\
49^{\circ} 26^{\prime} 65^{\prime \prime} \mathrm{O}\end{array}$ \\
\hline PP2 & $\begin{array}{l}\text { Cruzamento } \\
\text { (Próximo ao cruzamento de duas vias de tráfego in- } \\
\text { tenso, com fluxo médio de } 2.000 \text { veículos por hora) }\end{array}$ & $\begin{array}{l}25^{\circ} 42^{\prime} 65^{\prime \prime} \mathrm{S} \\
49^{\circ} 26^{\prime} 58^{\prime \prime} \mathrm{O}\end{array}$ \\
\hline PP3 & $\begin{array}{c}\text { Aquário } \\
\text { (Centro do Passeio Público, a aproximadamente } \\
350 \mathrm{~m} \text { de uma via de tráfego intenso) }\end{array}$ & $\begin{array}{l}25^{\circ} 42^{\prime} 54^{\prime} \mathrm{S} \\
49^{\circ} 26^{\prime} 73^{\prime \prime} \mathrm{O}\end{array}$ \\
\hline PP4 & $\begin{array}{l}\text { Viveiro Pelicano } \\
\text { (Próximo ao cruzamento de duas vias de tráfego in- } \\
\text { tenso, com fluxo médio de } 1.600 \text { veículos por hora) }\end{array}$ & $\begin{array}{l}25^{\circ} 42^{\prime} 45^{\prime \prime} \mathrm{S} \\
49^{\circ} 26^{\prime} 85^{\prime \prime} \mathrm{O}\end{array}$ \\
\hline
\end{tabular}

\section{Bosque Capão da Imbuia (BCI)}

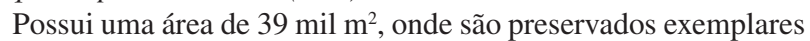
de imbuias, canelas e pinheiros centenários. O Bosque abriga o Museu de História Natural e foi classificado como área com vegetação densa.

Os pontos de amostragens selecionados para o Bosque Capão da Imbuia (BCI) estão detalhados na Tabela 2, sendo indicados através das coordenadas Sul (S) e Oeste (O). O fluxo médio de veículos representa a média horária para os períodos de tráfego intenso (início da manhã e final de tarde).

\section{Praça Ouvidor Pardinho (POP)}

A Praça Ouvidor Pardinho, que apresenta vegetação esparsamente densa, localiza-se no bairro Rebouças, também no centro da cidade de Curitiba. É uma área de lazer para a população do entorno, contendo uma piscina térmica aquecida, pista de caminhada, quadra poliesportiva, quadra de areia e área de lazer para as crianças. Destaca-se também por possuir um posto de saúde dentro de seus limites, onde grande parte da população de Curitiba busca atendimento regularmente. Neste local foram instalados apenas 2 amostradores por questões de segurança.

Os pontos de amostragens selecionados para Praça Ouvidor Pardinho (POP) estão detalhados na Tabela 3, sendo indicadas atra-
Tabela 2. Pontos de amostragem de BTEX definidos para o BCI

\begin{tabular}{|c|c|c|}
\hline Ponto & Localização & Coordenadas \\
\hline BCI1 & $\begin{array}{c}\text { Portaria } \\
\text { (Esquina de duas vias de tráfego moderado, próximo } \\
\text { a um ponto de ônibus, com fluxo médio de } 1.200 \\
\text { veículos por hora) }\end{array}$ & $\begin{array}{l}25^{\circ} 43^{\prime} 70^{\prime \prime} \mathrm{S} \\
49^{\circ} 21^{\prime} 92^{\prime \prime} \mathrm{O}\end{array}$ \\
\hline BCI2 & $\begin{array}{c}\text { Mata } 01 \\
\text { (A } 100 \text { m de uma via de tráfego moderado, com fluxo } \\
\text { médio de } 1100 \text { veículos por hora) }\end{array}$ & $\begin{array}{l}25^{\circ} 43 ' 63 " \mathrm{~S} \\
49^{\circ} 21^{\prime} 93 " \mathrm{O}\end{array}$ \\
\hline BCI3 & $\begin{array}{c}\text { Mata } 02 \\
\text { (Centro do Bosque, a aproximadamente } 200 \mathrm{~m} \text { de uma } \\
\text { via de tráfego moderado) }\end{array}$ & $\begin{array}{l}25^{\circ} 43^{\prime} 57^{\prime \prime} \mathrm{S} \\
49^{\circ} 21^{\prime} 92^{\prime \prime} \mathrm{O}\end{array}$ \\
\hline BCI4 & $\begin{array}{c}\text { Administração } \\
\text { (Via de tráfego moderado, com fluxo médio de } 1100 \\
\text { veículos por hora) }\end{array}$ & $\begin{array}{l}25^{\circ} 43^{\prime} 67^{\prime \prime} \mathrm{S} \\
49^{\circ} 22^{\prime} 04^{\prime \prime} \mathrm{O}\end{array}$ \\
\hline
\end{tabular}

vés das coordenadas Sul (S) e Oeste $(\mathrm{O})$. O fluxo médio de veículos representa a média horária para os períodos de tráfego intenso (início da manhã e final de tarde).

Tabela 3. Pontos de amostragem de BTEX definidos para a POP

\begin{tabular}{lcc}
\hline Ponto & Localização & Coordenadas \\
\hline \multirow{2}{*}{ POP1 } & Estação-Leste & $25^{\circ} 26^{\prime} 40^{\prime \prime} \mathrm{S}$ \\
& $\begin{array}{c}\text { Esquina da de duas vias de tráfego intenso, com } \\
\text { fluxo médio de 2.200 veículos por hora) }\end{array}$ & $49^{\circ} 16^{\prime} 17^{\prime \prime} \mathrm{O}$ \\
& Estação-Oeste & $25^{\circ} 26^{\prime} 40^{\prime \prime} \mathrm{S}$ \\
POP2 & (Via de intenso tráfego, com fluxo & $49^{\circ} 166^{\prime} 21^{\prime \prime} \mathrm{O}$ \\
& médio de 2.200 veículos por hora) & \\
\hline
\end{tabular}

\section{Amostragem}

As coletas de ar foram realizadas utilizando-se amostradores passivos, conhecidos como tubos de difusão da marca italiana Radielo $^{\circledR}$, compostos por uma malha cilíndrica de aço inoxidável, com abertura de 100 mesh e diâmetro de $5,8 \mathrm{~mm}$, preenchida com aproximadamente $530 \pm 30 \mathrm{mg}$ de carvão ativado com tamanho de partícula de 35-50 mesh.

Os amostradores passivos adsorvem os gases presentes na atmosfera de acordo com a Lei de Fick, que descreve o princípio de difusão de diferentes compostos. ${ }^{23}$ Após a exposição, que pode variar de 7 a 14 dias, dependendo do poluente e do ambiente a ser avaliado, apresenta como resultado o valor acumulado do poluente durante a amostragem.

Flutuações das concentrações diárias dos poluentes não podem ser determinadas por este método. No entanto, o alto valor de taxa de amostragem observado para uma variedade de compostos permite medidas exatas de concentração mesmo após exposições bastante curtas. Quinze min são suficientes para medir $0,1 \mathrm{mg} \mathrm{m}^{-3}$ de benzeno, por exemplo. ${ }^{24}$ Tais amostradores são muito sensíveis com limites de

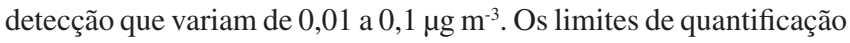
para 7 dias de exposição usualmente variam de 0,05 a $1 \mu \mathrm{g} \mathrm{m}^{-3}$, dependendo do composto. ${ }^{25}$ Os amostradores são protegidos, durante a amostragem, por tubos permeáveis chamados de corpos de difusão.

\section{Extração e análise}

Os analitos foram recuperados por meio da dessorção química, com $2 \mathrm{~mL}$ de dissulfeto de carbono, $\mathrm{CS}_{2}$. $\mathrm{O}$ dissulfeto de carbono foi adicionado aos amostradores, sendo em seguida agitados e deixados em repouso por $60 \mathrm{~min}$ em sua embalagem original de vidro. ${ }^{26}$

Os extratos foram então transferidos para frascos de $2 \mathrm{~mL}$ e posteriormente analisados por cromatografia a gás com detecção por ionização em chama - CG/DIC - (GC-2010, Shimadzu). Para a 
separação dos analitos, utilizou-se uma coluna capilar AT-624 (30 $\mathrm{m} \times 0,32 \mathrm{~mm} \times 1,8 \mu \mathrm{m}$ (Alltech, Belgium), cuja temperatura inicial foi mantida a $50{ }^{\circ} \mathrm{C}$ por $1 \mathrm{~min}$, em seguida elevada a $150{ }^{\circ} \mathrm{C}$ a uma velocidade de $10^{\circ} \mathrm{C}$ por minuto e mantida nesta temperatura por 1 min e, finalmente, elevada novamente até $250^{\circ} \mathrm{C}$ a $50^{\circ} \mathrm{C}$ por minuto. Injetor e detector foram mantidos a 250 e $260{ }^{\circ} \mathrm{C}$, respectivamente. Utilizou-se hidrogênio como gás de arraste e o volume injetado foi de $1 \mu \mathrm{L}$, no modo de injeção splitless. Cada amostra foi injetada em triplicata. Os limites de detecção e quantificação do método foram determinados para os BTEX e variaram de 0,15 a $0,27 \mu \mathrm{m}^{-3}$ e de 0,45 a $0,86 \mu \mathrm{m}^{-3}$, respectivamente.

A massa do analito presente no amostrador foi calculada por interpolação na equação da curva analítica de calibração, obtida a partir de uma mistura de padrões UST HC BTEX MIX (2000 $\mu \mathrm{g}$ $\mathrm{mL}^{-1} \mathrm{em}$ metanol, Sigma-Aldrich), que foi diluída nas concentrações de 0,$4 ; 1 ; 2,5 ; 4,7 ; 10$ e 17 ppm. As concentrações foram calculadas considerando-se fatores diferenciais como tempo de exposição, taxa de adsorção dos compostos e temperatura ambiente durante o período da amostragem, além da taxa de amostragem, que é característica de cada gás amostrado. ${ }^{24}$

\section{Avaliação preliminar da estrutura das plantas}

Com o objetivo de avaliar alguns parâmetros que podem estar relacionados com a presença dos poluentes estudados na atmosfera, seis indivíduos de Tillandsia stricta Sol. Ex Sims. (Bromeliaceae), espécie epífita conhecida pelos nomes populares de "cravo-do-mato, gravatazinho ou bromélia”, pré-existentes nas áreas de estudo foram selecionados. Estes indivíduos foram coletados a uma altura de 1,5 a 3,0 m, com exposição à luminosidade no sentido leste, sendo que a intensidade luminosa variou de 1.500 a 2.300 lux.

Os seguintes parâmetros foram analisados: espessura e estrutura dos tecidos da folha, e teor de clorofila (pigmento verde das células vegetais), o qual é receptor de energia luminosa na fotossíntese. ${ }^{27} \mathrm{O}$ material para a análise de clorofila, após a coleta, foi envolto por papel alumínio e mantido sob refrigeração, a $4{ }^{\circ} \mathrm{C}$. As amostras para estudo da estrutura interna da folha foram fixadas em FAA 70, que consiste em uma solução de formaldeído, ácido acético e etanol 70\% (90:5:5 em volume) e, após 1 semana, armazenados em etanol 70\% (V/V).

Para quantificar o teor de clorofila foram utilizados $28 \mathrm{mg}$ de material vegetal obtidos de três folhas de cada indivíduo, conforme Barnes et al.. ${ }^{28} \mathrm{~A}$ extração do pigmento foi feita com $5 \mathrm{~mL}$ de dimetilsulfóxido em tubos de ensaio, envoltos com papel alumínio e em banho-maria a $65^{\circ} \mathrm{C}$, por aproximadamente $6 \mathrm{~h}$, ou seja, até a extração completa do pigmento. Para a leitura das absorbâncias nos comprimentos de onda 648 e $665 \mathrm{~nm}$, foi utilizado um espectrofotômetro (Varian - Cary 50B10). Os valores obtidos foram multiplicados pelo volume do solvente utilizado $(5 \mathrm{~mL})$ e divididos pelo massa de folha por tubo de ensaio ( $28 \mathrm{mg}$ ), obtendo-se deste modo a concentração de cada pigmento por unidade de peso foliar em $\mu \mathrm{g} \mathrm{m}^{-1}$ que, poste-

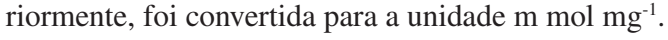

Para a análise da estrutura foliar lâminas permanentes foram confeccionadas a partir da inclusão em meta-acrilatoglicol (JB-4), conforme a técnica de Feder e O' Brien. ${ }^{29}$ Um micrótomo de rotação (utilizado para obtenção de secções histológicas) (Leica RM 2125) foi utilizado para obtenção das secções transversais, com espessura de $7 \mu \mathrm{m}$ que foram coradas com azul de toluidina a $0,05 \%$ e montadas em lâminas com resina sintética (Entellan $\left.{ }^{\circledR}\right)$. Empregou-se um fotomicroscópio (Olympus - BX 41) com captura de imagem e o software Image - Proplus para as mensurações das camadas dos tecidos foliares de 6 folhas.

Para todas as variáveis, foram primeiramente verificados os padrões das distribuições, através do teste Shapiro-Wilk (teste estatístico utilizado para verificar a distribuição de variáreis). Todas as variáveis se apresentaram em distribuição normal, sendo então possível a realização de inferências por meio de testes paramétricos. Em todas as análises foi aplicado o teste t-Student para testar a hipótese de que as médias dos parâmetros avaliados são equivalentes entre as plantas coletadas nas três áreas de estudo. Foram consideradas como significativas as diferenças em que $\mathrm{p} \leq 0,05$.

\section{RESULTADOS E DISCUSSÃO}

\section{Concentrações de BTEX nas áreas de estudo}

As concentrações de BTEX observadas nas três áreas de estudos estão apresentadas nas Tabelas 4, 5 e 6.

Na Tabela 4, estão mostrados os valores das concentrações de BTEX obtidas para o Bosque Capão da Imbuia (BCI), o qual apresenta uma vegetação densa com um fluxo aproximado de 21.700 veículos por dia circulando nas adjacências.

Tabela 4. Concentrações de BTEX $\left(\mu \mathrm{g} \mathrm{m}^{-3}\right)$ obtidas para os três períodos de amostragens realizadas em quatro pontos no Bosque Capão da Imbuia (BCI) $(\mathrm{A}=28 / 07$ a $04 / 08 / 08 ; \mathrm{B}=04 / 08$ a 10/08/08; $\mathrm{C}=10 / 08$ a 16/08/08)

Concentração $\left(\mu \mathrm{g} \mathrm{m}^{-3}\right)$

Composto Ponto BCI 1 Ponto BCI 2 Ponto BCI 3 Ponto BCI 4

\begin{tabular}{ccccccccccccc} 
& A & B & C & A & B & C & A & B & C & A & B & C \\
\hline benzeno & 9,9 & 5,4 & 2,6 & 3,3 & 3,6 & 3,2 & 2,7 & 3,5 & 1,8 & 4,0 & 3,3 & 2,8
\end{tabular}

$\begin{array}{lllllllllllll}\text { tolueno } & 14,2 & 12,0 & 9,5 & 4,6 & 6,5 & 5,6 & 4,4 & 7,4 & 3,6 & 6,7 & 6,5 & 5,1\end{array}$

$\begin{array}{lllllllllllll}\text { etilbenzeno } & 2,8 & 1,9 & 1,8 & 1,7 & 1,6 & 1,4 & 1,5 & 1,5 & 1,3 & 2,0 & 1,8 & 1,3\end{array}$

$\begin{array}{lllllllllllll}\text { m+p-xilenos } & 3,1 & 2,0 & 2,1 & 1,6 & 1,5 & 1,6 & 1,5 & 1,4 & 1,1 & 2,2 & 1,7 & 1,2\end{array}$

\begin{tabular}{lllllllllllll} 
o-xileno & 2,1 & 2,0 & 1,4 & 1,1 & 0,9 & 0,8 & 1,0 & 0,9 & 0,7 & 1,2 & 1,7 & 0,8 \\
\hline
\end{tabular}

Observa-se pela Tabela 4 que o ponto BCI 1 foi o que apresentou as maiores concentrações para todos os compostos, possivelmente devido às emissões provenientes dos veículos automotores trafegando pelas ruas adjacentes, cujo trânsito foi considerado intenso principalmente nos horários de pico (21.700 carros por dia). $\mathrm{O}$ amostrador em BCI 1 estava localizado muito próximo da via pública, sem qualquer barreira física ou uma cortina verde, por exemplo.

As concentrações de benzeno e tolueno registradas durante a primeira semana de amostragem para o ponto BCI 1 foram um pouco maiores que aquelas dos períodos seguintes, o que pode ser explicado pela diferença das condições climáticas. No primeiro período, houve menor volume de precipitação (verificou-se que em aproximadamente $35 \%$ do período da amostragem não houve incidência de chuva), o que pode ter ocasionado uma maior concentração deste composto na atmosfera. Em dias chuvosos esperar-se-ia menor concentração na atmosfera já que as gotas de chuva poderiam absorver as moléculas de benzeno, que apresentam solubilidade razoável em água. ${ }^{31}$ Para os demais pontos no BCI, a diferença não foi tão significativa devido à maior distância da fonte (rua).

O ponto de amostragem BCI 3 foi o que apresentou menores concentrações de BTEX, possivelmente por estar localizado no centro do bosque de vegetação densa. Segundo experimentos realizados por Song et al. ${ }^{15}$ a redução da concentração de BTEX em um ambiente é proporcional à quantidade de plantas presentes. O BCI 3 apresentou valores na ordem de 2 vezes inferiores para benzeno e tolueno, quando comparado com o BCI 1, fenômeno já relatado por Cetin et al. ${ }^{32}$

Com relação aos compostos etilbenzeno e xilenos, não foram observadas variações significativas entre as concentrações referentes aos pontos de amostragem $\mathrm{BCI} 2, \mathrm{BCI} 3, \mathrm{BCI} 4$, nos três períodos de amostragem. 
A Tabela 5 apresenta os valores das concentrações de BTEX detectadas nas três amostragens realizadas durante o período de 28/07 a 16/08/08 no Passeio Público (PP), o qual apresenta uma vegetação pouco densa com um fluxo aproximado de 33.250 veículos por dia circulando nas adjacências.

Tabela 5. Concentrações de BTEX $\left(\mu \mathrm{g} \mathrm{m}^{-3}\right)$ obtidas para os três períodos de amostragens realizadas em quatro pontos no Passeio Público (PP) (A = 28/07 a $04 / 08 / 08 ; B=04 / 08$ a $10 / 08 / 08 ; C=10 / 08$ a $16 / 08 / 08$ )

\begin{tabular}{|c|c|c|c|c|c|c|c|c|c|c|c|c|}
\hline \multirow{3}{*}{ Composto } & \multicolumn{12}{|c|}{ Concentração $\left(\mu \mathrm{g} \mathrm{m}^{-3}\right)$} \\
\hline & \multicolumn{3}{|c|}{ Ponto PP 1} & \multicolumn{3}{|c|}{ Ponto PP 2} & \multicolumn{3}{|c|}{ Ponto PP 3} & \multicolumn{3}{|c|}{ Ponto PP 4} \\
\hline & A & B & $\mathrm{C}$ & A & B & $\mathrm{C}$ & A & B & $\mathrm{C}$ & A & $\mathrm{B}$ & $\mathrm{C}$ \\
\hline senzeno & 3,3 & 6,2 & 5,4 & 5,5 & 7,7 & 4,2 & 3,7 & 2,5 & 3,3 & 4,4 & 4,2 & 4,9 \\
\hline tolueno & 4,3 & 7,7 & 8,4 & 5,7 & 8,4 & 3,2 & 3,9 & 4,7 & 3,4 & 4,6 & 7,9 & 5,7 \\
\hline etilbenzeno & 1,0 & 1,6 & 1,4 & 1,5 & 1,7 & 1,3 & 1,4 & 1,5 & 1,4 & 1,6 & 1,5 & 1,4 \\
\hline $\mathrm{m}+\mathrm{p}$-xilenos & 1,4 & 1,9 & 1,5 & 1,8 & 2,0 & 1,4 & 1,6 & 1,5 & 1,6 & 1,9 & 1,6 & 1,5 \\
\hline o-xileno & 1,0 & 1,2 & 1,0 & 1,1 & 1,5 & 1,1 & 1,1 & 0,9 & 0,9 & 1,2 & 1,1 & 1,0 \\
\hline
\end{tabular}

Pode-se observar, na Tabela 5, que as maiores concentrações de BTEX foram encontradas nos pontos PP1 e PP2, durante o segundo período de amostragem (04/08 a 10/08/08), possivelmente devido às emissões trazidas pela direção preferencial do vento, provenientes dos veículos automotores trafegando pelas ruas adjacentes (33.250 carros por dia), de onde os amostradores estavam muito próximos.

$\mathrm{O}$ ponto de amostragem PP3 foi o que apresentou menores concentrações de BTEX, cerca de 2 vezes menores que PP2, provavelmente devido ao ponto estar localizado no centro do Passeio Público, o que segundo Song et al. ${ }^{15}$ pode explicar os valores mais baixos de concentração de BTEX.

Observou-se também que, durante a amostragem em dias mais chuvosos ( $2^{\mathrm{a}}$ semana), as concentrações de benzeno nos amostradores localizados na periferia da área de estudo (PP1, PP2, PP4) foram superiores ao ponto localizado no centro da área (PP3). Supõe-se que isto possa ser devido ao fato da ocorrência de um maior engarrafamento no trânsito provocado por um aumento do fluxo de veículos na região central. Além disso, aquele período coincidiu com o início das aulas referentes ao $2^{\circ}$ semestre letivo, provocando um aumento da emissão de benzeno, conforme já evidenciado por Buczynska et al.. ${ }^{26}$

Não foram observadas variações significativas de concentração para os compostos etilbenzeno e xilenos entre os pontos PP1, PP2, PP3 e PP4.

A Tabela 6 apresenta os valores das concentrações de BTEX determinadas no período de 28/07 a 16/08/08 na Praça Ouvidor Pardinho (POP), a qual apresenta uma vegetação esparsamente densa, com um fluxo aproximado de 35.520 veículos por dia circulando pelas adjacências.

Tabela 6. Concentrações de BTEX $\left(\mu \mathrm{g} \mathrm{m}^{-3}\right)$ obtidas para os três períodos de amostragens realizadas em quatro pontos na Praça Ouvidor Pardinho (POP) $(A=28 / 07$ a 04/08/08; B = 04/08 a 10/08/08; C = 10/08 a 16/08/08)

\begin{tabular}{lcccccc}
\hline \multirow{2}{*}{ Composto } & \multicolumn{5}{c}{ Concentração $\left(\mu \mathrm{g} \mathrm{m}^{-3}\right)$} \\
& P & B & C & A & B & C \\
\hline benzeno & 5,7 & 7,0 & 7,2 & 6,2 & 4,6 & 5,9 \\
tolueno & 5,8 & 6,7 & 7,0 & 6,5 & 9,7 & 7,4 \\
etilbenzeno & 1,8 & 1,5 & 1,8 & 1,9 & 2,0 & 1,7 \\
m+p-xilenos & 2,3 & 1,8 & 2,1 & 2,3 & 2,5 & 2,1 \\
o-xileno & 1,5 & 1,3 & 1,3 & 1,4 & 1,6 & 1,5 \\
\hline
\end{tabular}

Observa-se pela Tabela 6 que todas as concentrações de BTEX detectadas em POP1 e POP2 apresentam valores muito próximos para todos os compostos, devido possivelmente à proximidade de localização.
Observa-se, pelas Tabelas 4, 5, e 6, que a concentração de tolueno referente à $2^{\mathrm{a}}$ amostragem apresentou, de maneira geral, valores superiores quando comparados à $1^{\mathrm{a}}$ e $3^{\mathrm{a}}$ semana de amostragem. Entre as possíveis contribuições está a menor temperatura registrada ao longo de todo o período. Segundo Cetin et al., ${ }^{32}$ é esperado que as concentrações de BTEX sejam maiores quando a temperatura ambiente for menor. De fato, a temperatura média do $2^{\circ}$ período foi de $13,9^{\circ} \mathrm{C}$, inferior aos 16,7 e $16,9^{\circ} \mathrm{C}$ referentes ao $1^{\circ}$ e $3^{\circ}$ períodos da amostragem, respectivamente.

A Tabela 7 apresenta os valores das concentrações médias de BTEX detectadas ao longo dos três períodos de amostragem nas três áreas públicas estudadas em Curitiba (BCI, PP e POP).

Tabela 7. Tabela comparativa das concentrações médias de BTEX encontradas nas diferentes áreas públicas avaliadas na cidade de Curitiba-PR, Brasil, de $28 / 07$ a $16 / 08 / 08$

\begin{tabular}{lccc}
\hline \multirow{2}{*}{ Composto } & \multicolumn{3}{c}{ Concentração média $\left(\mu \mathrm{g} \mathrm{m}^{-3}\right)$} \\
& $\begin{array}{c}\text { Bosque Capão da } \\
\text { Imbuia (BCI) }\end{array}$ & $\begin{array}{c}\text { Passeio Público } \\
\text { (PP) }\end{array}$ & $\begin{array}{c}\text { Praça Ouvidor } \\
\text { Pardinho (POP) }\end{array}$ \\
\hline Benzeno & 3,9 & 4,6 & 6,1 \\
Tolueno & 7,2 & 6,5 & 7,2 \\
Etilbenzeno & 1,7 & 1,4 & 1,8 \\
m+p-xileno & 1,7 & 1,6 & 2,2 \\
o-xileno & 1,2 & 1,1 & 1,5 \\
\hline
\end{tabular}

Observa-se, nesta tabela, que a maior concentração média de benzeno foi detectada na $\operatorname{POP}\left(6,1 \mu \mathrm{g} \mathrm{m}^{-3}\right)$, provavelmente devido ao maior número de veículos que trafegam na região (35.520 carros por dia) e à menor densidade de vegetação. As concentrações registradas no PP e no BCI foram bastante similares, embora o trânsito seja mais intenso no PP, que fica em uma região mais central. Embora o BCI esteja em uma área com menor circulação de veículos, um dos pontos de amostragem (BCI1) foi propositalmente instalado ao lado de uma parada de ônibus urbano, o que elevou a média da concentração obtida no local. No entanto, similarmente nesses dois pontos, concentrações mais elevadas foram observadas nas proximidades das fontes de emissão, e valores menores foram registrados nos pontos internos, com vegetação mais densa, o que sugere que a sua presença possa funcionar como uma "cortina verde" de proteção à poluição.

Segundo Cetin et al., ${ }^{32}$ outras variáveis que podem contribuir para estas variações de concentrações nos locais avaliados são a topografia do terreno e a existência de construções de grande porte, que podem interferir em até $60 \%$ das condições ambientais de um local, em função da dificuldade de dispersão destes poluentes.

Com relação a outro estudo realizado em Curitiba, que também apresenta medidas de BTEX na atmosfera de uma área residencial (com densidade de tráfego média), ${ }^{39}$ os valores obtidos neste trabalho foram todos mais elevados. Para contextualizar as concentrações de BTEX registradas em Curitiba-PR, a Tabela 8 apresenta os valores médios de BTEX obtidos por vários estudos realizados em centros urbanos de algumas cidades do mundo, tendo como principal fonte as emissões veiculares.

Observa-se, na Tabela 8, que os pontos estudados na cidade de Curitiba (BCI, PP e POP) apresentaram valores de concentrações médias de BTEX inferiores aos encontrados nas cidades de São Paulo e Santiago, possivelmente devido à diferença na intensidade do tráfego. As concentrações de BTEX em Curitiba são similares àquelas observadas nas cidades de Hong Kong e La Coruña, sendo que nesta última a concentração média de benzeno é inferior se comparada com BCI, PP e POP.

A Legislação Ambiental Brasileira (tanto Federal, quanto Estadual ou Municipal) não define parâmetros comparativos de contaminação 
Tabela 8. Comparação das concentrações médias de BTEX registradas em diversos estudos realizados em vários centros urbanos em diferentes países

\begin{tabular}{|c|c|c|c|c|}
\hline Cidade & Descrição do local & Composto & $\begin{array}{l}\text { Concentração } \\
\text { média }\left(\mu \mathrm{g} \mathrm{m}^{-3}\right)\end{array}$ & Ref. \\
\hline $\begin{array}{l}\text { São Paulo } \\
\text { (Brasil) }\end{array}$ & $\begin{array}{l}\text { centro da cidade, } \\
\text { próximo ao trânsito } \\
\text { intenso }\end{array}$ & $\begin{array}{c}\text { Benzeno } \\
\text { Tolueno } \\
\text { Etilbenzeno } \\
\text { m+p-xileno } \\
\text { o-xileno }\end{array}$ & $\begin{array}{c}17 \\
28 \\
6,0 \\
19 \\
6,2\end{array}$ & 6 \\
\hline $\begin{array}{l}\text { Santiago } \\
\text { (Chile) }\end{array}$ & $\begin{array}{l}\text { centro da cidade, } \\
\text { próximo ao trânsito } \\
\text { intenso }\end{array}$ & $\begin{array}{c}\text { Benzeno } \\
\text { Tolueno } \\
\text { Etilbenzeno } \\
\text { m+p-xileno } \\
\text { o-xileno }\end{array}$ & $\begin{array}{l}15 \\
30 \\
6,5 \\
25 \\
8,9\end{array}$ & 6 \\
\hline $\begin{array}{l}\text { Hong Kong } \\
\text { (China) }\end{array}$ & $\begin{array}{c}\text { Universidade } \\
\text { Politécnica de Hong } \\
\text { Kong }\end{array}$ & $\begin{array}{c}\text { Benzeno } \\
\text { Tolueno } \\
\text { Etilbenzeno } \\
\text { m+p-xileno } \\
\text { o-xileno }\end{array}$ & $\begin{array}{l}4,8 \\
29 \\
3,1 \\
3,2 \\
2,8\end{array}$ & 33 \\
\hline $\begin{array}{l}\text { La Corunha } \\
\text { (Espanha) }\end{array}$ & $\begin{array}{l}\text { avenida de trânsito } \\
\text { intenso, com prédios } \\
\text { de } 8 \text { a } 10 \text { andares }\end{array}$ & $\begin{array}{c}\text { Benzeno } \\
\text { Tolueno } \\
\text { Etilbenzeno } \\
\text { m+p-xileno } \\
\text { o-xileno }\end{array}$ & $\begin{array}{l}3,4 \\
24 \\
3,3 \\
5,1 \\
2,7\end{array}$ & 34 \\
\hline $\mathrm{BCI}$ & $\begin{array}{c}\text { área residencial, } \\
\text { trânsito moderado, } \\
\text { vegetação densa }\end{array}$ & $\begin{array}{c}\text { Benzeno } \\
\text { Tolueno } \\
\text { Etilbenzeno } \\
\text { m+p-xileno } \\
\text { o-xileno }\end{array}$ & $\begin{array}{l}3,9 \\
8,4 \\
1,7 \\
1,7 \\
1,2\end{array}$ & $\begin{array}{c}\text { Este } \\
\text { trabalho }\end{array}$ \\
\hline PP & $\begin{array}{c}\text { Área central, trânsito } \\
\text { intenso, vegetação } \\
\text { pouco densa }\end{array}$ & $\begin{array}{c}\text { Benzeno } \\
\text { Tolueno } \\
\text { Etilbenzeno } \\
\text { m+p-xileno } \\
\text { o-xileno }\end{array}$ & $\begin{array}{l}4,6 \\
6,5 \\
1,4 \\
1,6 \\
1,1\end{array}$ & $\begin{array}{c}\text { Este } \\
\text { trabalho }\end{array}$ \\
\hline POP & $\begin{array}{c}\text { Área central, trânsito } \\
\text { intenso, vegetação } \\
\text { esparsamente densa }\end{array}$ & $\begin{array}{c}\text { Benzeno } \\
\text { Tolueno } \\
\text { Etilbenzeno } \\
\text { m+p-xileno } \\
\text { o-xileno }\end{array}$ & $\begin{array}{l}6,1 \\
7,2 \\
1,8 \\
2,2 \\
1,5\end{array}$ & $\begin{array}{c}\text { Este } \\
\text { trabalho }\end{array}$ \\
\hline
\end{tabular}

ambiental para os compostos de BTEX (benzeno, tolueno, etilbenzeno e xilenos) para ambiente externo. No âmbito internacional, a União Européia estabelece para benzeno (comprovadamente cancerígeno) o limite de $5 \mu \mathrm{g} \mathrm{m} \mathrm{m}^{-3}$ como valor seguro (de acordo com a Directiva UE 2000/69/EC para $2010^{35}$ ). Por isso, este valor foi adotado neste trabalho como referência.

A Figura 1 apresenta as concentrações de benzeno encontradas em cada ponto de amostragem em Curitiba-PR, tomando como base a média das três amostragens realizadas em cada ponto.

Observa-se na Figura 1 que os pontos BCI1, PP2, POP1 e POP2 apresentaram valores de concentração média para o benzeno superiores ao valor limite estabelecido pela União Européia (Directiva UE 2000/69/EC ${ }^{35}$ ), podendo estar relacionados ao elevado fluxo veicular naquelas regiões de estudo, conforme já abordado por vários autores em diversos estudos. ${ }^{1,2,17}$ Adicionalmente, o ponto PP1 apresentou concentração de benzeno no limite recomendado. Tais pontos são exatamente os de menor densidade vegetativa, o que pode sugerir que a vegetação pode funcionar como uma barreira natural para a dispersão da poluição.

Para confirmar a fonte de emissão de BTEX, utilizou-se a relação proposta por diferentes autores, ${ }^{36-38}$ que propuseram que razões menores que 2,$7 ; 1,8$ e 0,9 entre os compostos tolueno e benzeno ( $\mathrm{T} / \mathrm{B}), \mathrm{m}+\mathrm{p}$ xileno/benzeno $(\mathrm{m}+\mathrm{p}-\mathrm{x} / \mathrm{B})$ e o-xileno/benzeno $(\mathrm{o}-\mathrm{x} / \mathrm{B})$, respectivamente seriam indicativas de fontes veiculares de emissão (Tabela 9).

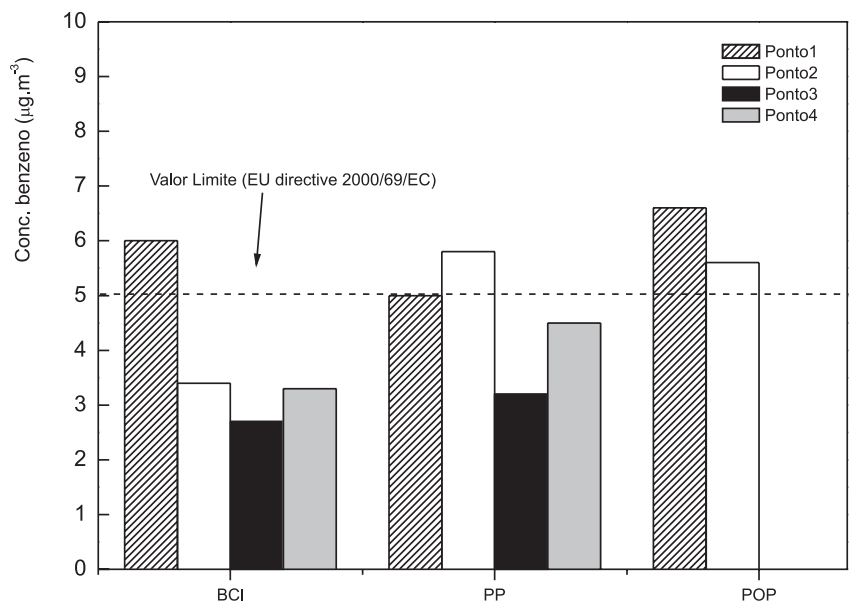

Figura 1. Concentrações de benzeno medidas entre 28/07/08 a 16/08/08 nas três áreas de estudo de Curitiba-PR, comparadas com o do valor limite (5 $\mu \mathrm{g} \mathrm{m}^{-3}$ ) estabelecido pela União Européia (Directiva UE 2000/69/EC ${ }^{35}$ ). BCI = Bosque Capão da Imbuia; $P P=$ Passeio Público; $P O P=$ Praça Ouvidor Pardinho

Tabela 9. Razão tolueno/benzeno (T/B), $m+p$-xileno/benzeno $(m+p-X / B)$ e o- xileno/benzeno (o-X/B), para as áreas de estudo compreendidas pelo $\mathrm{BCI}$, PP e POP considerando a concentração média das três amostragens

\begin{tabular}{|c|c|c|c|c|c|}
\hline & \multicolumn{5}{|c|}{ Bosque Capão da Imbuia (BCI) } \\
\hline & BCI1 & $\mathrm{BCI} 2$ & $\mathrm{BCI} 3$ & BCI4 & $\begin{array}{c}\text { Indicativo de emissão } \\
\text { veicular }\end{array}$ \\
\hline $\mathrm{T} / \mathrm{B}$ & 1,98 & 1,65 & 1,92 & 1,85 & $<2,70^{36}$ \\
\hline$m+p-X / B$ & 0,40 & 0,44 & 0,48 & 0,51 & $<1,80^{37}$ \\
\hline \multirow[t]{3}{*}{$\mathrm{o}-\mathrm{X} / \mathrm{B}$} & 0,30 & 0,26 & 0,30 & 0,36 & $<0,90^{38}$ \\
\hline & \multicolumn{5}{|c|}{ Passeio Público (PP) } \\
\hline & PP1 & PP2 & PP3 & PP4 & $\begin{array}{c}\text { Indicativo de emissão } \\
\text { veicular }\end{array}$ \\
\hline $\mathrm{T} / \mathrm{B}$ & 1,36 & 1,00 & 2,28 & 1,33 & $<2,70^{36}$ \\
\hline$m+p-X / B$ & 0,32 & 0,29 & 0,47 & 0,36 & $<1,80^{37}$ \\
\hline \multirow[t]{3}{*}{$\mathrm{o}-\mathrm{X} / \mathrm{B}$} & 0,22 & 0,21 & 0,31 & 0,24 & $<0,90^{38}$ \\
\hline & \multicolumn{5}{|c|}{ Praça Ouvidor Pardinho (POP) } \\
\hline & \multicolumn{2}{|c|}{ POP1 } & \multicolumn{2}{|c|}{ POP2 } & $\begin{array}{c}\text { Indicativo de emissão } \\
\text { veicular }\end{array}$ \\
\hline $\mathrm{T} / \mathrm{B}$ & \multicolumn{2}{|c|}{0,98} & \multicolumn{2}{|c|}{1,41} & $<2,70^{36}$ \\
\hline $\mathrm{m}+\mathrm{p}-\mathrm{X} / \mathrm{B}$ & \multicolumn{2}{|c|}{0,32} & \multicolumn{2}{|c|}{0,41} & $<1,80^{37}$ \\
\hline $\mathrm{o}-\mathrm{X} / \mathrm{B}$ & \multicolumn{2}{|c|}{0,21} & \multicolumn{2}{|c|}{0,27} & $<0,90^{38}$ \\
\hline
\end{tabular}

De acordo com a Tabela 9, a fonte de BTEX nas áreas de estudo em Curitiba-PR é a emissão veicular, já que as razões de T/B, m+p$\mathrm{X} / \mathrm{B}$ e o-X/B são menores que as propostas na literatura.

Ações de gerenciamento de trânsito parecem ser, portanto, necessárias na área central de Curitiba, embora Buczynska et al ${ }^{26}$ tenham demonstrado, em seu estudo realizado na cidade de Antuérpia (Bélgica), que nem todas as modificações são ambientalmente relevantes. O aumento no engarrafamento devido a mudanças na direção do trânsito levou a um aumento da concentração de BTEX na região. Monitoramentos realizados demonstraram um aumento da concentração de benzeno e etilbenzeno em 35 e 77\%, respectivamente.

\section{Consequências sobre as folhas da Tillandsia stricta}

Os resultados referentes às análises realizadas nas folhas de Tillandsia stricta demonstraram que houve diferença significativa entre os três pontos de coletas no que se refere ao teor de clorofila total e mensuração dos tecidos. 
Em relação à clorofila total, os resultados demonstraram menor média para as folhas coletadas na POP, seguida de folhas coletadas no PP e BCI. Para o parênquima clorofiliano (tecido composto por células parenquimáticas que contêm cloroplastos), o menor valor também foi observado na POP (Tabela 10).

Tabela 10. Média \pm desvio padrão do teor de clorofila total e parênquima clorofiliano das folhas da Tillandsia stricta Sol. Ex Sims coletadas nas diferentes áreas públicas estudadas na cidade de Curitiba - PR

\begin{tabular}{lcc}
\hline Área de estudo & Clorofila total $\left(\mathrm{m} \mathrm{mol} \mathrm{mg}^{-1}\right)$ Parênquima clorofiliano $(\mu \mathrm{m})$ \\
\hline POP & $0,72 \pm 0,12$ & $320,00 \pm 46,03$ \\
PP & $1,24 \pm 0,19$ & $448,30 \pm 65,07$ \\
BCI & $1,84 \pm 0,78$ & $429,82 \pm 63,57$ \\
\hline
\end{tabular}

Na comparação dos teores de clorofila obtidos nos três pontos de coleta (Tabela 10), o teste t de Student demonstrou diferença significativa entre POP e BCI $(p=0,00)$ e entre POP e PP $(p=0,00)$; e diferença não significativa entre $\mathrm{BCI}$ e $\mathrm{PP}(\mathrm{p}=0,10)$. Verificou-se também que quanto maior a concentração de BTEX, menor é o teor de clorofila total foliar (fazendo uma relação entre as Tabelas 7 e 10). Esta evidência já foi identificada por Kammerbauer et al., ${ }^{11}$ quando realizaram ensaios com plantas de Ricinus communis expostas à emissão veicular em vias públicas urbanas, observando principalmente manchas, clorose e necrose nas folhas.

Ainda de acordo com a Tabela 10, os resultados referentes aos valores encontrados para o parênquima clorofiliano demonstraram menor média para as folhas coletadas na POP, seguida das folhas coletadas na $\mathrm{BCI}$ e PP. O teste t demonstrou diferença significativa entre POP e BCI $(p=0,01)$ e entre POP e PP $(p=0,00)$; e diferença não significativa entre $B C I$ e $P P(p=0,63)$. Quando os resultados apresentados nas Tabelas 7 e 10 são novamente relacionados, observa-se que quanto maior a concentração dos poluentes menor é a espessura de parênquima clorofiliano. Tal constatação está em concordância com Kammerbauer et al., ${ }^{11}$ que também confirmaram diferenças significativas para a concentração de clorofila das plantas.

\section{CONCLUSÕES}

Os resultados deste estudo indicaram que as concentrações de BTEX observadas nas áreas estudadas de Curitiba-PR são provenientes de emissões veiculares e suficientes para representar um risco de exposição para a população local, principalmente devido ao efeito carcinogênico do benzeno. A continuidade do estudo por um período de tempo mais longo poderá ser feita para melhor quantificar a extensão dessa exposição.

As variáveis climáticas (direção predominante dos ventos, velocidade dos ventos, umidade relativa, temperatura), as características urbanísticas e a densidade de vegetação do local representam fatores significativos para a dispersão e redução da concentração de BTEX em áreas externas. Observaram-se concentrações de BTEX significativamente menores em áreas de vegetação densa, chegando a ser até duas vezes menores para as substâncias benzeno e tolueno.

Constatou-se que quanto maior a concentração de BTEX na área de estudo, menores são os teores de clorofila e espessura do parênquima clorofiliano da espécie Tillandsia stricta. A utilização de plantas bioindicadoras parece, portanto, ser bastante útil na avaliação dos efeitos da poluição atmosférica urbana. O desenvolvimento de um sistema de monitoramento do ar baseado no uso de bioindicadores vegetais, associados à rede existente de monitoramento convencional da qualidade do ar, pode representar um avanço significativo na garantia da qualidade ambiental dos municípios da região.

$\mathrm{O}$ incentivo à adoção do transporte solidário, bem como o de- senvolvimento de sistemas de transporte que causem menos impacto ao meio ambiente, pode significar uma melhora na qualidade do ar de grandes centros urbanos. Além disso, a criação de legislações ambientais aplicáveis, o monitoramento dos poluentes perigosos à saúde dos seres vivos e o controle ambiental pelos órgãos competentes são fundamentais.

\section{MATERIAL SUPLEMENTAR}

A Figura 1S, que ilustra e evidencia as diferentes densidades de vegetação por meio da vista aérea das áreas estudadas em Curitiba-PR, está disponível em http://qumicanova.sbq.org.br, com acesso livre, na forma de arquivo PDF.

\section{AGRADECIMENTO}

À Petróleo Brasileiro S/A - PETROBRAS.

\section{REFERÊNCIAS}

1. Becher, R.; Toxicol. Lett. 1996, 86, 155.

2. Hansen, A. B.; Palmgren, F.; Sci. Total Environ. 1996, 189/190, 451.

3. Cocheo, V.; Sacco, P.; Boaretto, C.; De Saeger, E.; Perez Ballesta, P.; Skov, H.; Goelen, E.; Gonzalez, N.; Baeza Caracena, A.; Nature 2000, 404, 141.

4. Bertoni, G.; Ciuchini, C.; Pasini, A.; Tappa, R.; J. Environ. Monit. 2002, 4, 903 .

5. http://www.opas.org.br, acessada em Março 2007.

6. Gee, I. L.; Sollars, C. J.; Chemosphere 1998, 36, 2497.

7. Gioda, A.; Aquino Neto, F. R.; Rev. Brasindoor 2001, V, 20.

8. Avigo Jr., D.; Godoi, A. F. L.; Janissek, P. R.; Makarovska, Y.; Krata, A.; Potgieter-Vermaak, S.; Balint, A.; Van Grieken, R.; Godoi, R. H. M.; Anal. Bioanal. Chem. 2008, 391, 1459.

9. http://www.detran.pr.gov.br, acessada em Agosto 2008.

10. http://www.urbs.curitiba.pr.gov.br, acessada em Agosto 2008.

11. Kammerbauer, H.; Selinger, H.; Ziegler-Joens, A.; Roemmmelt, R.; Knoppik, D.; Hock, B.; Environ. Pollut. 1987, 48, 235.

12. Kammerbauer, J.; Dick, T.; Arch. Environ. Contam. Toxicol. 2000, 39, 161.

13. Viskari, E. L.; Holopainen, T.; Karenlampi, L.; Environ. Pollut. 2000, 107, 99.

14. Viskari, E. L.; Surakka, J.; Pasanen, P.; Mirme, A.; Kössi, S.; Ruuskanen J.; Holopainen, J. K.; Environ. Pollut. 2000, 107, 89.

15. Song, J. E.; Kim, Y. S.; Sohn, J. Y.; J. Physiol. Antropol. 2006, 26, 599.

16. Hiatt, M. H.; Environ. Sci. Tecnol. 1999, 33, 4126.

17. Keymeulen, R.; Schamp, N.; Vanlangenhove, H.; Chemosphere 1995, $31,3961$.

18. Cape, J. N.; Environ. Pollut. 2003, 122, 145.

19. Kapusta, P.; Szarek-Lukaszewska, G.; Godzik, B.; Environ. Pollut. 2006, 143, 285.

20. Moraes, R. M.; Tese de Doutorado, Universidade de São Paulo, Brasil, 1999.

21. Azevedo, A. A.; Tese de Doutorado, Universidade de São Paulo, Brasil, 1995.

22. Zabiegala, B.; Górecki, T.; Przyk, E.; Namiésnik, J.; Atmos. Environ. 2002, 36, 2907

23. Cox, R. M.; Environ. Pollut. 2003, 126, 301.

24. http://www.radiello.it, acessada em Setembro 2007.

25. Pennequin-Cardinal, A.; Plaisance, H.; Locoge, N.; Ramalho, O.; Kirchner, S.; Galloo, J.-C.; Rev. Atmos. Environ. 2005, 39, 2535.

26. Buczynska, A. J.; Krata, A.; Stranger, M.; Godoi, A. F. L.; KontozovaDeutsch, V.; Bencs, L.; Naveau, I.; Roekens, E.; van Grieken, R.; Atmos. Environ. 2009, 43, 311 . 
27. Raven, P. H.; Evert, R. F.; Eichhorn, S. E.; Biologia vegetal, 6 ${ }^{\mathrm{a}}$ ed., Guanabara Koogan: Rio de Janeiro, 2001.

28. Barnes, J. D.; Environ. Exp. Bot. 1992, 32, 85.

29. Feder, N.; O’Brien, T. P.; Am. J. Bot. 1968, 55, 123.

30. Sakai, W. S.; Annu. Rev. Microbiol. 2006, 19, 241.

31. IPCS - International Programme on Chemical Safety 1993; WHO (Environmental Health Criteria; 155).

32. Cetin, E.; Odabasi, M.; Seyfioglu, R.; Sci. Total Environ. 2003, 312, 103.

33. Ho, K. F.; Lee, S. C.; Sci. Total Environ. 2000, 289, 145.

34. Derwent, R. G.; Atmos. Environ. 2000, 34, 297.
35. Directive 2000/69/EC, OJ L 313, 13.12.2000, p. 12.

36. Brocco, D.; Fratarcangeli, R.; Lepore, L.; Petricca, M.; Venrrone, I.; Atmos. Environ. 1997, 31, 551.

37. Stevenson, K. J.; Stacey, B.; Willis, P. G.; Air quality at Heathrow Airport Annual Report for 1996, AEA Technology 1997.

38. Guicherit, R.; Sci. Total Environ. 1997, 205, 201.

39. Godoi, R. H. M.; Avigo Jr., D.; Campos, V. P.; Tavares, T. M.; de Marchi, M. R. R.; Van Grieken, R.; Godoi, A. F. L.; Water, Air, Soil Pollut: Focus 2009, 9, 171. 


\section{POLUIÇÃO E A DENSIDADE DE VEGETAÇÃO: BTEX EM ALGUMAS ÁREAS PÚBLICAS DE CURITIBA -}

\section{PR, BRASIL}

Ana Flavia Locateli Godoi* e Ricardo Henrique Moreton Godoi

Departamento de Engenharia Ambiental, Universidade Federal do Paraná, Rua Francisco H. dos Santos, 100, 81531-990 Curitiba - PR, Brasil

Roosevelt de Azevedo e Leila Teresinha Maranho

Universidade Positivo, Rua Prof. Pedro V. Parigot de Souza, 5300, 81280-330 Curitiba -PR, Brasil

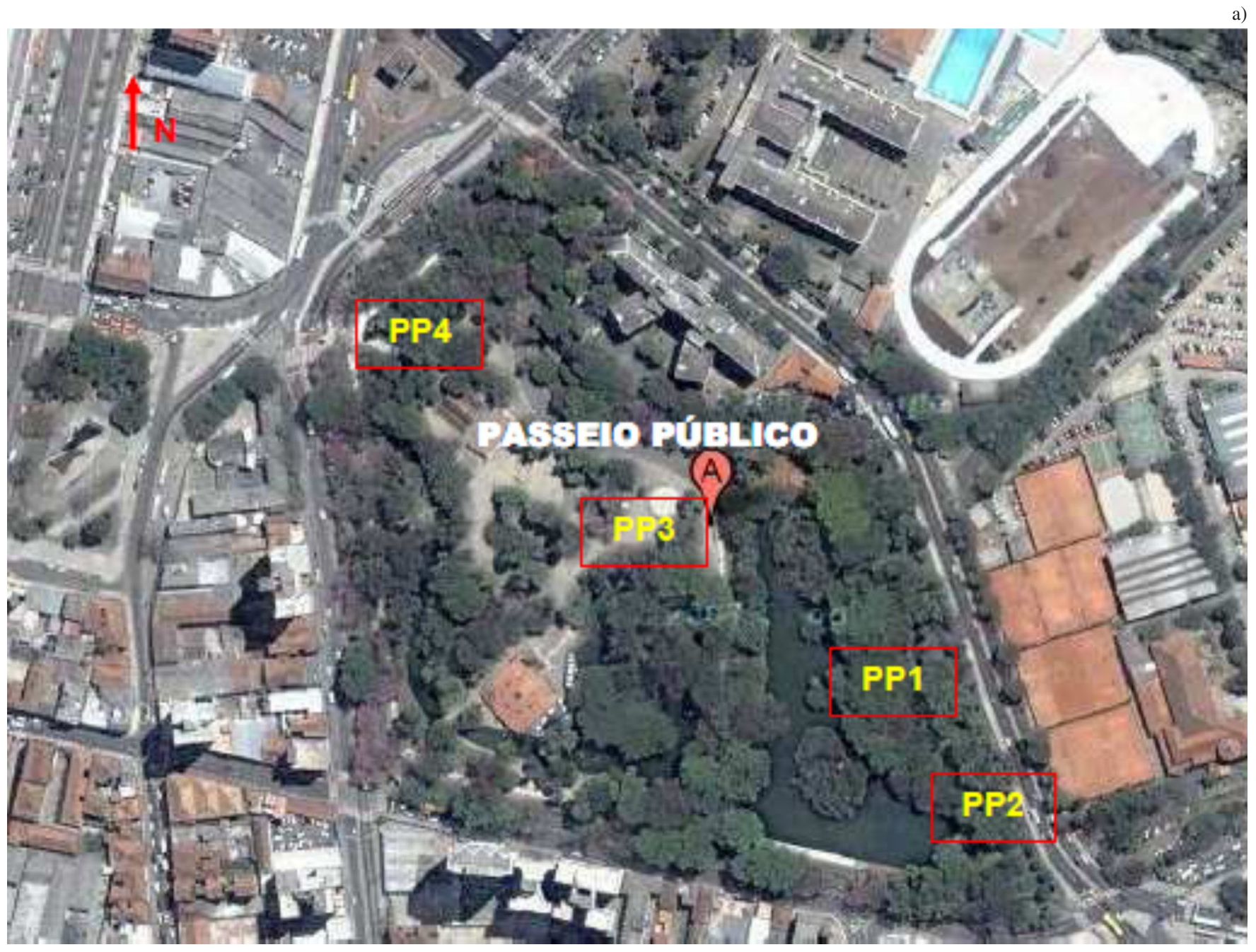

Figura 1S. Vista aérea das áreas de amostragem em Curitiba-PR com indicação da localização dos pontos de amostragem; a) Passeio Público - PP1, PP2, PP3 e PP4; b) Bosque Capão da Imbuia - BCI1, BCI2, BCI3 e BCI4; c) Praça Ouvidor Pardinho - POP1 e POP2. Fonte: Google Maps em 07/08/2008 
b)

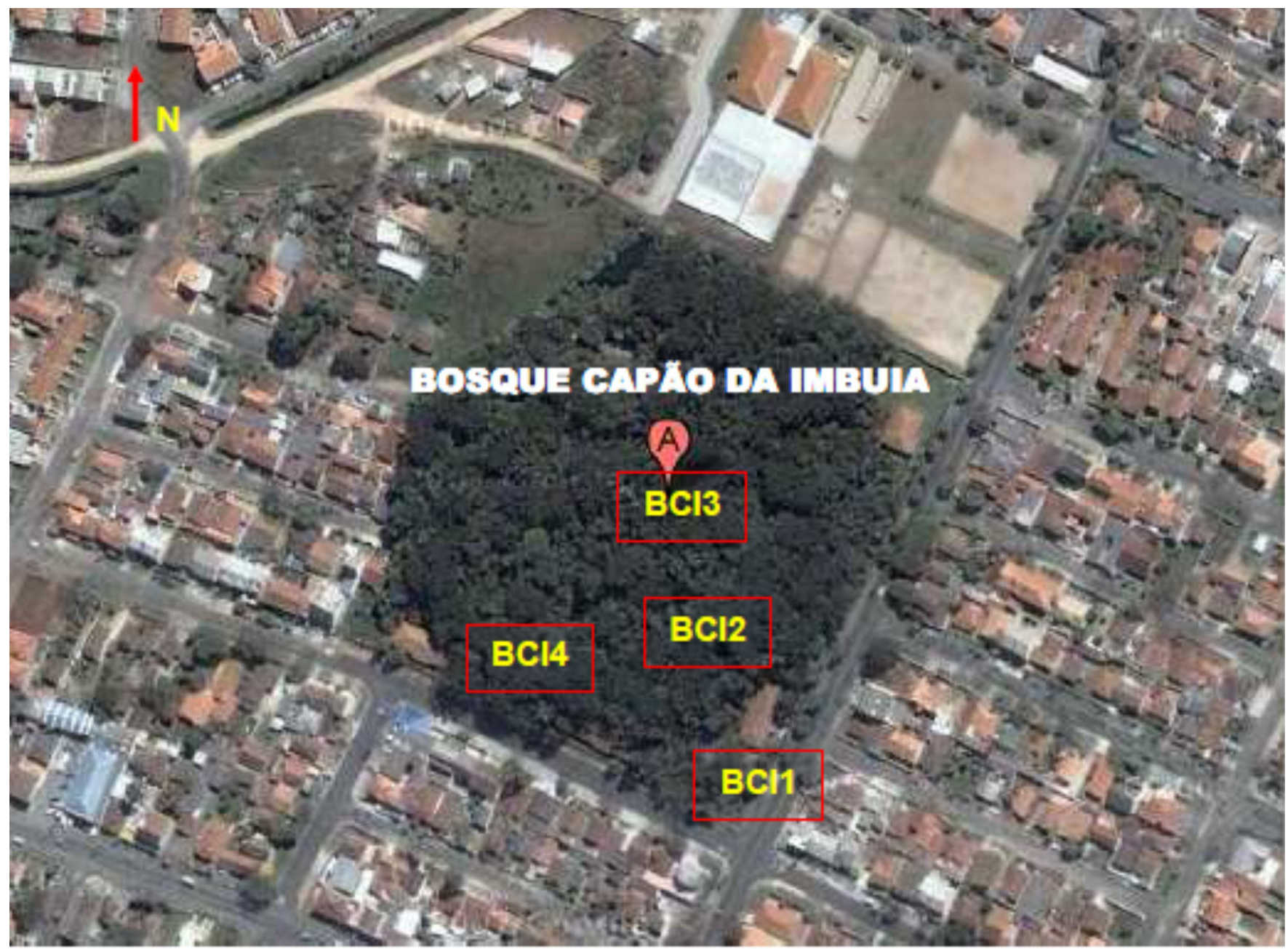

Figura 1S. Vista aérea das áreas de amostragem em Curitiba-PR com indicação da localização dos pontos de amostragem; a) Passeio Público - PP1, PP2, PP3 e PP4; b) Bosque Capão da Imbuia - BCI1, BCI2, BCI3 e BCI4; c) Praça Ouvidor Pardinho - POP1 e POP2. Fonte: Google Maps em 07/08/2008 


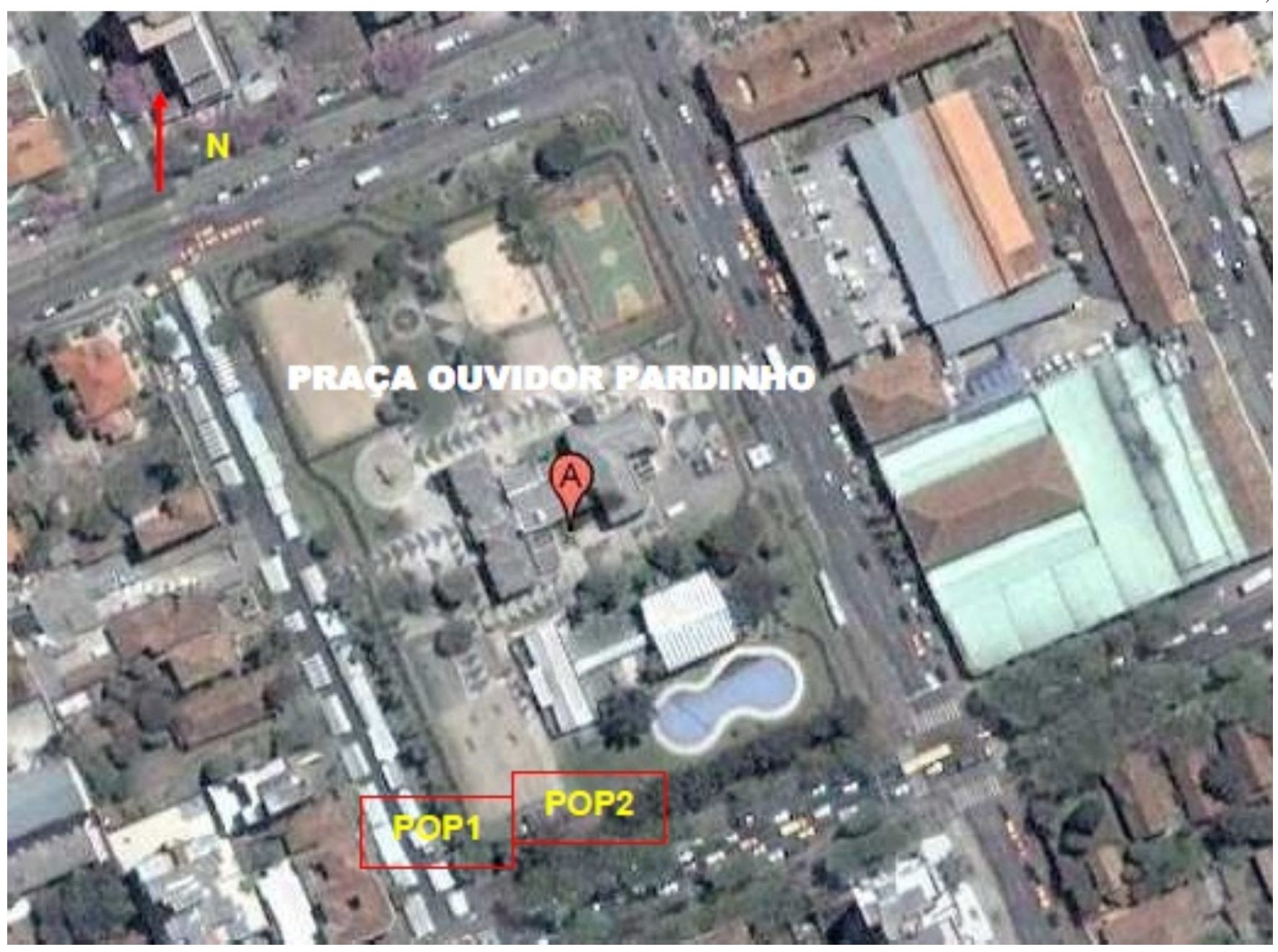

Figura 1S. Vista aérea das áreas de amostragem em Curitiba-PR com indicação da localização dos pontos de amostragem; a) Passeio Público - PP1, PP2, PP3 e PP4; b) Bosque Capão da Imbuia - BCI1, BCI2, BCI3 e BCI4; c) Praça Ouvidor Pardinho - POP1 e POP2. Fonte: Google Maps em 07/08/2008 